Pensamiento Crítico No. 7, pág. 49 - 69

\title{
Evidencias para el Cambio en un Mundo Globalizado, a partir de la Realidad Objetiva \\ Ridberth Ramírez Miranda
}

Resumen: Desde que el mundo es mundo, todo ha ido evolucionando de forma cuántica -aunque aparentemente continua- y producido procesos de acumulación que han dado lugar a la más compleja realidad que hoy contemplamos, analizamos y de la que partimos con el propósito de cambiarla por otra aún mejor con nuestra creatividad. Los mayores grados de espiritualidad, de conocimientos, de velocidad en la sucesión de los hechos que cambian cada vez, lógicamente, más vertiginosamente, como consecuencia de la mayor complejidad y del protagonismo por parte del hombre, cada vez más «creador», junto con la incipiente comprensión del fenómeno de la evolución, son sólo muestras aisladas, pero importantes evidencias de lo que hoy significa la vida en su desenvolvimiento.

Esto es posible, en la actual etapa de la misma, porque la gran riqueza o complejidad de relaciones alcanzada, que caracteriza nuestra época actual de transición nos proporciona una capacidad de conocimiento y entendimiento con suficientes antecedentes, logrando que nuestro cerebro, gracias a nuestra posibilidad de conocer y recordar la historia, acumule el necesario número de imágenes de referencia como para empezar a ser reflexivamente consciente tanto de lo que pasa como de lo que viene y, consecuentemente, protagonista en mayor medida del proceso de evolución y cambio.

Palabras claves: Realidad, cambio,. Evolución, complejidad, creatividad, globalización 


\section{Ridberth Ramírez Miranda}

\section{La búsqueda de un contrato social diferente}

El sistema social humano y la realidad, están en continuo proceso de evolución, que no siempre es lineal, o sea que no se desenvuelve en igual grado de intensidad o progresión, sino que en épocas de transición o salto de nivel de conciencia como el actual, hasta que este nuevo nivel se alcanza se suceden hechos inciertos, imprevisibles, sorprendentes e inesperados; es algo así como si la dimensión tiempo, junto con la superior dosis de creatividad y creciente libertad, sin olvidar la integración que crea complejidad, trabando todo, hubiera producido una aceleración impresionante que nos impide prever ese único futuro que hoy vertiginosamente ya empieza a ser presente.

Para quienes sepan imaginarse mejor lo que es una película de cine, con imágenes estáticas constituidas por fotogramas independientes, cuya visión seguida nos da la impresión de movimiento y continuidad ininterrumpida, les resultará más fácil entender el proceso desigual y no lineal que caracteriza a la evolución de que hablamos, en la que una sucesión de hechos diferentes y diferenciados -como los fotogramas- ofrecen y alcanzan la impresión de rápida continuidad que vivimos actualmente, como continuación de períodos en los que incluso la evolución parecía desenvolverse hasta en "cámara lenta", o mostrando los fotogramas como cosas aisladas y por separado.

Por tanto, la complejidad presente en esta fase del proceso es el resultado lógico del avance de la universalización en la que progresivamente ha entrado nuestro planeta, persiguiendo la nueva viable realidad a través de una transición que nos permita alcanzar el nuevo sentido que le corresponde, que ya empieza a estar presente en cuestiones y problemas actuales.

Este nuevo sentido está involucrado con la inducción e integración de hechos, conocimientos, «medios» y funciones, que antes de esta fase parecían ser distintos; y con la interdependencia holística o unitaria, como consecuencia y resultado de épocas como la actual, en las que se acelera la propia evolución, implicándonos en el intento de consolidar un salto o cambio de nivel hacia otro superior, en una época imparable e inexorable de transición que no terminará hasta alcanzar la visión inmaterial como «acción», que corresponde a su nuevo sentido unitario o genérico axioma, en el que la deducción volverá a ser posible.

Los mayores conocimientos de que ya se dispone, relaciones, oportunidades, tecnologías y sistemas, aportando avances de todo orden con su integración, inducción o interrelación; y hasta del superior grado de ética, libertad y creatividad, necesarias en el actual dinámico estadio para poder seguir creando y evolucionando con coherencia, están dando lugar a un nuevo hombre. También a un mundo más interdependiente, único y necesariamente más complejo, solidario y coherente, al ser cada día más las dificultades de los demás también nuestros 


\section{Evidencias para el cambio en un mundo globalizado, a partir de la realidad objetiva}

problemas; y a un hecho, la competencia universal o planetaria de todos con todos.

$Y$ es este incremento de las relaciones e interrelaciones, cualitativo y cuantitativo, entre civilizaciones, continentes, países, personas, razas, ideologías, instituciones, disciplinas, conocimientos, objetos y actividades diferentes, quien nos permitirá vivir nuestra singular aventura humana, entendiendo la realidad cada vez más como acción y, por lo tanto, como un proceso dinámico de mayor diversidad, complejidad, conocimiento, comunión, solidaridad, cooperación, interdependencia, creatividad y continua información-comunicación, ampliada por un mayor número y diverso universo de «medios» formalizados que aumentan la corporeidad de las personas, su propio «medio» y el «medio social» compartido por todos.

Este cambio, entendido con la nueva visión de una realidad como acción (por lo tanto superando la visión material que sólo veía cosas: físicas, estáticas, aisladas, no relacionadas e incomunicadas), nos va a permitir alcanzar el diagnóstico acertado que representa una ruptura, transición o verdadero salto de nivel en el proceso de desenvolvimiento de la cuántica historia de la evolución, desde su primitivo, más lento y sencillo principio, hasta alcanzar la dinámicamente frenética situación actual de rápidos y continuos cambios, necesitado de mayor asimilación, para así alcanzar primero, y mantener después, la armonía que corresponde a los sucesivos y superiores niveles de conciencia.

El diagnóstico es más fácil de lo que se podría suponer a primera vista, puesto que la principal dificultad que padecemos proviene del hecho de que los problemas no están siendo analizados ni afrontados con la «mente» y los «medios» de que ya disponemos, de lo que resulta una incertidumbre o incoherencia que solamente superaremos cuando recuperemos la armonía, coherencia o unidad de sentido dinámico entre «mente-medios-problemas», en sintonía con el nivel de conciencia vigente.

Esto a su vez reclama la estrategia apropiada al caso, para ser capaces de generar y ofrecer las soluciones que necesitamos precisamente ahora, superando la inercia de las concepciones e ideas obsoletas que quedaron atrás, pero siguen vivas -aunque estén-, para ser reemplazadas por las que corresponden a una superadas visión inmaterial y dinámica de la realidad que, en lugar de ver «cosas» y «objetos», como hacía la visión Material -por lo tanto, repito, físicos, estáticos aislados e incomunicados-, entiende la dinámica de la evolución como acción que se manifiesta y actúa en el seno de ámbitos coherentes de relaciones entre el «ente», propiamente dicho, y su «medio» o campo de relaciones, en el que se desenvuelve y actúa la acción, en sintonía de sentido con su correspondiente nivel de conciencia.

En efecto, para nadie pasa inadvertido la circunstancia de que un conjunto de hechos, por muy peculiares o diferentes que sean entre sí en las distintas zonas del mundo, dan lugar a un diagnóstico cuando todos ellos, partes integrantes del mismo todo, admiten que las enriquecedoras diferencias, no solamente tienen que existir, sino que aumentan en épocas en las que por fin la unidad y la diversidad, tanto como la peculiaridad, no solamente son una 


\section{Ridberth Ramírez Miranda}

necesidad, sino que también son una fundamental condición para que continúe y se acreciente la creatividad y complejidad, que mantiene y enriquece la propia evolución hacia un mayor grado de perfección.

En realidad, para avanzar en momentos como este de transición, y por lo tanto de especial confusión (siguiendo a los chinos, en cuyo idioma crisis se representa por los ideogramas WEI-JI, el primero de los cuales significa «Peligro» y el segundo "Oportunidad»), tendríamos que empezar por ser capaces de discernir perfectamente los síntomas que corresponden a la sucesión de crisis y aquellos que, por contener potencialidad de futuro y formar ya parte del nuevo nivel, nos pueden permitir consolidar la transición y el diagnóstico que buscamos y necesitamos apremiantemente.

Definiendo así la estrategia que conviene a cada parte diferente que compone el variado todo universal, contribuyendo a alcanzar la nueva fase de deducción desde un nivel de sentido o axioma general para, induciendo posteriormente los distintos sentidos, procedentes del mismo origen, a los que ha dado lugar el espacialismo - en todos los cuales subyace el sentido del axioma del que provienen, puesto que de él se dedujeron-, pasar al siguiente nivel o nuevo axioma, al inducir o integrar los correspondientes sentidos otra vez en uno solo, para que la evolución siga su curso dinámico hacia niveles superiores de integración y, por lo tanto, de mayor complejidad e interrelación.

Y eso es justamente lo que voy a intentar desarrollar y explicar de forma sencilla, comprensible y al día, en las siguientes páginas, con fe y certeza de que éste es el momento en el que vivimos, y que si lo entendemos nacerá en todos nosotros la esperanza y las soluciones que tanto necesitamos.

La racionalidad me obligará a abordar múltiples cuestiones aparentemente desconexas (los síntomas y «medios»); pero de los cuales debe surgir un diagnóstico provisional y válido para nuestra época, circunstancias, civilización, cultura, medio y peculiaridad individual, porque la objetividad y uniformidad propiamente dichas, nunca existen como tales en un cambiante y variado proceso real de evolución. Cuando éste tiene como punto de partida las características de diversidad, unión, aceleración, peculiaridad, amplitud e intensidad en las personas, hechos y mutaciones como la que actualmente vivimos, máxime en un mundo cuya visión aún está muy lejos de ser coincidente, ni siquiera entre padres e hijos, que lógicamente comparten más próximamente un mismo entorno, sociedad o «medio», la coincidencia es factible.

Nos proponemos abordar, la interpretación y el tratamiento de la variada realidad como acción y proceso de importante inmaterialización, universalización, creatividad, superior diversidad, integración o inducción, incluso entre las distintas especialidades del conocimiento, necesitado de mayor comprensión, respeto, interrelación, unificación, ética y comunicación de relaciones, con un lenguaje sencillo, con los que procuraremos reflejar la ineludible y absoluta necesidad de relegar la visión material estática. 


\section{Evidencias para el cambio en un mundo globalizado, a partir de la realidad objetiva}

Comprendiendo que solamente siendo fieles a la completa, compleja, diversa y verdadera naturaleza de las personas y de la propia realidad, podremos alcanzar la visión holística -todo junto- en problemas que, aunque todavía prevalezcan y abunden las visiones materiales y aisladas, hoy ya son globales, junto con la verdadera dimensión de nuestro «cuerpo actuante», formado no solamente por nuestros miembros (brazos, manos, dedos, piernas, fuerza física) y sentidos (vista, olfato, oído, tacto o gusto), sino también, y fundamentalmente, por nuestros conocimientos, técnicas, tecnologías, instrumentos o instituciones, en un conjunto que nos permite resolver cuestiones con su real aportación y cooperación a la acción con sentido, para en definitiva contribuir interviniendo activa y creativamente a su satisfactoria resolución.

Nuestros ojos dominan un determinado campo de visión; pero si conocemos el manejo de un microscopio, para penetrar en el mundo de lo pequeño; y de un telescopio, que nos permite divisar lo lejano -si también disponemos de los conocimientos y los instrumentos apropiados-, qué duda cabe que nuestro campo de visión, con nuestros mismos ojos, se amplía enormemente; y lo mismo podríamos decir de la capacidad de memoria o cálculo del cerebro de una persona que sabe y tiene a su alcance una herramienta informática debidamente programada.

El mismo cerebro, con técnica, resulta ser infinitamente más rápido y potente si el conocimiento y dominio de instrumentos a nuestro servicio, amplían nuestro cuerpo activo y actuante, del que forma parte tanto nuestra mente como todo lo demás relacionado con el conocimiento y todos los «medios» formalizados, que tantísimo mejoran nuestro potencial de visión, proyección, actuación y los resultados finales a nuestro alcance, ante circunstancias problemáticas e insolubles, que si sólo dispusiéramos de nuestro cuerpo físico sin las aportaciones complementarias que le convierten en nuestro «cuerpo actuante», para así afrontar la realidad como acción que es lo que es en definitiva.

Entendamos bien, pues, que el «cuerpo actuante» de las personas, propiamente dicho repito- no son sólo sus miembros y sentidos, sino además todos ellos cuando son enriquecidos y ampliados con el conocimiento formalizado por el cerebro o los miembros externos o «medios» que, en definitiva, nos dan la dimensión, tamaño y potencia de nuestra verdadera capacidad potencial de actuar.

Al ser la realidad en primer y último lugar acción con sentido, dirigida por el conocimiento, disposición y dominio de todo lo que forma parte de nuestro «cuerpo actuante», o sea, constituida por múltiples ámbitos coherentes de relación, en mayor cantidad conforme nuestra formación, formalización de conocimientos y la evolución avanza y, por lo tanto, la eficacia y la complejidad que domina es más automática, mayor y mejor, como también los «medios» a nuestra disposición o el grado de comunicación e información, relación práctica, instrucción, solidaridad y ética que intervenga de hecho, todo es más perfecto y cada vez más fácil si hemos adaptado nuestra mentalidad, como ya impone una evolución más inmaterial, universal y 


\section{Ridberth Ramírez Miranda}

dinámicamente aún más rápida y compleja que la que correspondió a la anterior fase.

Debiendo ser la fase siguiente la administración objetiva y global de las acciones conjuntas del conocimiento para el beneficio de la sociedad.

\section{La superioridad de lo inmaterial sobre lo material}

Como parte de lo que podríamos calificar de verdadero cambio cualitativo en el proceso de hominización de las personas, también debemos constatar la gran evidencia que supone el enorme salto al primer plano de una nueva riqueza, esta vez inmaterial, que transforma la valía y preparación de lo que hoy reconocemos ya como la superioridad de los recursos humanos sobre los recursos materiales.

El hecho lo tenemos que relacionar con el fin de la civilización de la producción, llevada a cabo en la forma en la que nos la planteó la primera revolución industrial y la aparición de esa sociedad de relaciones post-industrial de la información o el conocimiento, aunque en realidad teniendo hoy millones de datos carecemos en la práctica de información, a pesar de las relaciones que se derivan, de la informática, las telecomunicaciones, la conectividad y el conocimiento formalizado, dando lugar a lo que prefiero llamar, en un sentido más amplio, «sociedad de personas».

Este término contiene todo lo que significan los demás calificativos que separadamente en mi opinión-, no pasan de ser unas buenas definiciones reduccionistas y limitadas, propias de una época de transición como la que vivimos, que aún no reconoce en su comportamiento que a años luz de distancia, el bienestar, salud y felicidad que persigue la evolución, no es otro que el de todas las personas sin excepción, y que esto no es alcanzable sin amor, ética, coherencia y verdadera solidaridad o unión.

Y hablo de una sociedad de personas porque a la información o al conocimiento también hay que añadirle el importantísimo papel que, sobre todo a partir de ahora, van a desempeñar en una sociedad interrelacionada, la interdependencia, competencia, grado de comunicación o conectividad, creatividad, libertad, imaginación, coherencia, formación, ética, permeabilidad necesaria, mayor solidaridad, infraestructuras e intercomunicación, en la que los conocimientos son también pieza clave. En cualquier caso, todo son evidencias más difíciles de "ver", por el hecho de que, los recursos inmateriales no tratándose de algo físico, de algo material como su propio nombre indica, resultan intangibles, indivisibles e invisibles por su propia naturaleza.

La cuestión es que ya podemos afirmar que los países a la vez ricos en creatividad, tecnológicamente hábiles para aplicar lo que descubren o saben, y que también están formados y organizados, son los más prósperos y los que se van colocando a la cabeza; y no los que tienen materias primas, como petróleo, metales, buen clima o incluso dinero, oro y diamantes, pero que se olvidan en demasiadas ocasiones de la superior importancia, tanto de los bienes inmateriales, como sobre todo de la preparación de los recursos humanos, en los que destaca por vital la 


\section{Evidencias para el cambio en un mundo globalizado, a partir de la realidad objetiva}

necesidad de formación práctica en todas las personas.

Observemos, por ejemplo, como Japón o Suiza, comprando desde el acero hasta el petróleo, sin apenas recursos naturales ni suficiente tierra cultivable, diseminado el primero en varios cientos de islas, que además no inició su despegue desde una postura de riqueza, destruido por una guerra, pero que supo empezar copiando para después añadir organización, diseño, conocimiento, ingenio, creatividad, mucho trabajo y aplicación a lo que hacían con dominio, constancia, práctica e imaginación - en definitiva recursos inmateriales-, supo así mejorar el primitivo modelo, con lo que han logrado llegar a ser nada menos que una de las primeras potencias industriales más desarrolladas, singulares e importantes del mundo, careciendo prácticamente de Recursos Materiales.

En consecuencia, uno de los hechos más característicos y, sin embargo por lo visto más difíciles de captar y percibir en este momento, resulta ser el inexorable e imparable proceso de inmaterialización y humanización que aceleradamente se va imponiendo en el mundo. Algunas veces este proceso se desarrolla en grandes industrias que se automatizan y convierten prácticamente en importantes sociedades de servicios, y otras, se advierte en hechos tan elocuentes como la progresiva sustitución de la mecánica por la electrónica, la miniaturización o la desmaterialización en sistemas o productos que antes necesitaban mayor cantidad de recursos naturales o físicos, y hoy sobre todo "inteligencia" para así ofrecer indudables ventajas y mejores comportamientos.

Si comparamos la fibra óptica con el cobre como conductor, para comunicar una misma cantidad de información, el peso necesario de materia es sorprendentemente menor no sólo gracias a la miniaturización, sino sobre todo a la desmaterialización y, consecuentemente, disminución de peso del propio producto utilizado para cumplir una misma función.

Por su lado, la fabricación personalizada, con programas que sobre la marcha convierten en una realidad los gustos o deseos de su futuro dueño o consumidor, con planteamientos basados en el Stock Cero, «Just in Time» (justo a tiempo) y otras técnicas aplicadas ya en varias actividades productivas y de servicios, comprenderemos mejor lo que también todos deberíamos estar haciendo para sintonizar con nuestro «tiempo» si queremos competir, con independencia del país o continente donde vivamos o queramos hacerlo.

Lo inmaterial es por naturaleza invisible, intangible, intocable, inapropiable e indivisible, y aún podríamos añadir más calificativos que, ciertamente, imponen una nueva visión dinámica de la realidad y, consecuentemente, reclaman otra mentalidad que corresponde a la realidad como acción, otra manera de actuar y, por lo tanto, una nueva estrategia y un nuevo hombre en definitiva. Lo fundamental es darnos cuenta de que esto nos afecta a todos, sin excluir a nadie.

En consecuencia, todas estas evidencias y su indiscutible presencia e influencia tienen que estimulamos a ejercitar verdaderos esfuerzos de comprensión, que muchas veces nos obligan a 


\section{Ridberth Ramírez Miranda}

un real y difícil giro o adaptación de nuestra mentalidad, o, en otras palabras, a empezar en la práctica por hacer nuestra la nueva visión inmaterial, como acción dinámica, holística y coherente de la realidad, que ha sustituido a la visión material, que sobre todo veía «cosas» y objetos aislados, teniendo en cuenta que todo esto es un proceso nada fácil de cambiar al tener que forzar una nueva mentalidad, de difícil aceptación si no se capta claramente y nos esforzamos en lograrlo y, sin embargo, absolutamente necesaria para sintonizar con la viabilidad de la realidad que nos ha tocado vivir.

La miniaturización y la electrónica no solamente hacen las cosas cada vez más pequeñaspor lo tanto con menos material-, sino que también nos ofrecen continuamente una impresionante integración, gracias a la cual un mismo objeto realiza ahora varias funciones, cuando con otros pasan a formar parte de un mismo sistema; resulta curioso que hasta hace poco todo esto fuera impensable; hoy, sin embargo, en cada vez más numerosos e importantes procesos, se ha producido la integración o inducción entre cosas e ideas que nada tenían que ver entre sí.

Por todo ello, y cada vez más y en mayor medida, la creatividad y los programas o sistemas lógicos, son los que principalmente determinan el coste de los productos, que, repito, progresivamente serán proporcionalmente más eficaces, de fácil manejo, inmateriales, económicos e integrados, para además resolver así de manera más rápida, fácil y mejor un mayor número de funciones, y encima al alcance de más personas.

Otro ejemplo de inmaterialización que me parece eficaz e ilustrativo es el de una industria relojera como la Suiza, cuyas pasadas dificultades han sorprendido a todos, empezando por los propios suizos, pocas personas dudarían de su bien ganado prestigio en cuanto a calidad, precisión o diseño de sus relojes, $y$, sin embargo, esta industria hoy esta evolucionando aceleradamente como consecuencia del cambio tecnológico que resulta de sustituir la mecánica por la electrónica, en forma de nueva tecnología que impone una diferente concepción y simplificación en el número de piezas mecánicas, reemplazadas por «inteligentes» componentes electrónicos, necesarios para que un producto resuelva mejor y más económicamente incluso muchas más funciones.

El hecho es que, bien lejos de Europa, alguien descubrió la manera de hacer relojes con cinco sistemas electrónicos en lugar de las 900 piezas mecánicas que como media tenían los relojes convencionales en todo el mundo; y como reunir cinco elementos siempre es más fácil que hacerlo con 900, y encima ofrecen a menor coste una mayor cantidad de funciones (fecha, cronómetro, segundero, despertador, día de la semana, fase de la luna, hora en otros países, temperatura, brújula, radio, memorización de teléfonos, aviso de citas, etc.), la electrónica poco a poco ganó el terreno a la mecánica, en lo que no deja de ser también un claro, imparable e indiscutible proceso de inmaterialización.

En este caso los propios suizos no se han podido sustraer a este planteamiento para poder 


\section{Evidencias para el cambio en un mundo globalizado, a partir de la realidad objetiva}

competir, a la vista de sus ventajas y evidencias, cosa que está volviendo a equilibrar la competencia, adoptando esta modalidad como una solución propia y sobre todo manteniendo la reputación de sus marcas y diseños, recurriendo para ello no sólo a la electrónica sino también al arte del reloj joya y de enorme calidad, que añade prestigio a quien lo lleva y le libera del trabajo de darle cuerda todos los días, al funcionar con pilas y la ayuda del cuarzo.

\section{La necesidad de rediseñar el sistema humano}

Lo curioso es que el hombre, que se empeñaba en rediseñar su sistema humano para hacerlo más racional, por ejemplo aprovechando mejor los residuos y subproductos de un proceso cualquiera -reciclándolos para poder utilizarlos nuevamente como materia prima-; o que aspira a un mayor rendimiento por unidad de recurso utilizado, como ocurre por ejemplo con los procesos de miniaturización, hasta ahora no haya caído en la cuenta de que lo que en realidad está haciendo es desnivelar el fiel de la balanza en favor de las aportaciones Inmateriales, en relación a la menor importancia relativa que significan los bienes materiales.

La tendencia, pues, a la inmaterialización se ve favorecida por la continua miniaturización, que nos ofrece cada día de forma pronunciada la propia electrónica. Hoy, cualquier aparato, instrumento o equipo ocupa menos espacio, necesita menos cantidad de material, consume menos energía y, paradójicamente, hace cosas y mejor e incluso cuesta menos dinero, en el marco de una economía en la que otros productos y factores son progresivamente más onerosos.

Por otro lado, la integración de funciones también elimina un cierto número de piezas o elementos, al ser todas o parte de estas resueltas por un solo componente o sistema, que frecuentemente amplía, facilita o mejora, y hasta resulta más económico y fácil de manejar; imaginando la oficina del futuro, donde la computadora es poca cosa sin la fundamental facilidad de comunicarse, podemos ver cómo también la integración invade todas las áreas, convirtiéndose en un elemento indispensable y polivalente, capaz de cumplir múltiples funciones.

Así, ciertos sistemas integrados operan indistintamente con voz, datos, textos, gráficos, imágenes fijas o móviles, como el fax, fotografías, dibujos, diseños o películas, en una tendencia que no ha hecho nada más que empezar, puesto que pronto la computadora será un verdadero multimedia y, al mismo tiempo, un Terminal de comunicaciones, desde donde estemos y en todo momento.

Por otra parte y gracias a la transportabilidad, la realidad de la conectividad entre redes, y su facilidad para congeniar con otros computadoras, televisores, satélites, cables coaxiales, transmisión de paquetes, red digital de servicios integrados, fibra óptica, microondas, o el resto del espectro radioeléctrico en sus distintas formas, sin olvidar las tecnologías de la Información que garantizan el sonido, la imagen, la compresión de información o las velocidades que se 


\section{Ridberth Ramírez Miranda}

alcanzan, tanto en el proceso como en la memorización, transmisión, localización, almacenamiento o tratamiento de la información impresa, vocal, musical o gráfica, conforman ya una única trama o urdimbre de Información.

Desde que se ha puesto en marcha este reiteradamente aludido proceso de universalización, inmaterialización e integración, que, repito, aceleradamente va sustituyendo la mecánica por la electrónica, en nuestra mentalidad no nos cogerá por sorpresa saber que un televisor que tenía 2.000 piezas hoy tiene 400 menos; ni que un chip en una máquina de coser sustituye, él solo, nada menos que a 300 piezas mecánicas cuando no a muchísimas más.

Por otra parte, los procesos de inmaterialización, y superior intervención de la miniaturización y creatividad, que en este primer comentario solamente pretendo que no pasen inadvertidos, están también muy estrechamente relacionados con los continuos e importantes fenómenos de inducción o integración, que ya iremos especialmente comentando por su fundamental trascendencia en las circunstancias de la evolución que nos ha correspondido vivir.

Cuando todo empieza a tener relación con todo lo demás, en muchos casos surgen, como una nueva concepción, los planteamientos que anticipativamente se conciben con una modularidad que nos permite ampliar o añadir nuevas funciones, conforme estas perfecciones o posibilidades van siendo posibles.

Este hecho, cuya importancia resulta capital para entender el proceso de aumento de complejidad a que está sometida la realidad en su evolución, se manifiesta continuamente en múltiples formas. Así el fenómeno de la integración se va afianzando en cuestiones como las siguientes:

El hombre con su «medio» particular, fundiéndose en una única cultura y, por lo tanto, aumentando su conocimiento y su formación orientada a la práctica, o sea, a la acción que resuelve sus problemas o cuestiones, es principalmente la consecuencia de un mayor conocimiento e integración de entes, antes aislados e independientes y que hoy forman sistemas al compartir una misma unidad de sentido.

Lo material combinado con lo inmaterial, como es el caso de la «ferretería» del computador, que no es nada sin su software o parte inmaterial, está dando lugar a máquinas capaces de simultanear aplicaciones multiuso y multitarea, incluso de diferente naturaleza: la voz, la memorización, el diseño, la comunicación, los textos, los cálculos, las imágenes fijas como las fotos, el fax, el télex, el correo electrónico, la transferencia de ficheros, las imágenes móviles como las películas, videoconferencia o video, sin olvidar la música, el sonido o la voz sintética, ni la alta definición en las mismas, teléfonos, ordenadores, grabadores, proyectores, televisores, la consulta de bancos de datos y de información de todo tipo, almacenada en soportes ópticos o magnéticos, el envío de señales vía radio, teléfono celular, láser, microondas, satélite, cables coaxiales o de fibra óptica, la edición electrónica incluso a distancia y tantas cosas más.

Lo natural y lo artificial, como ocurre con nuestro lenguaje y el que entienden las 


\section{Evidencias para el cambio en un mundo globalizado, a partir de la realidad objetiva}

máquinas con las que interactivamos, últimamente con la virtud de simultanear sistemas operativos y sus lenguajes, o la traducción automática de un idioma a otro, así como el «esperanto» que hablan todas las máquinas y medios, que no es otro que la digitalización, hacen el resto.

Los continuos «matrimonios» entre tecnologías, de lo que son paradigmas: la información automatizada o informática; las telecomunicaciones y la informática, familiarmente conocida como telemática; la radio y las computadoras, ofreciendo imágenes en barrido lento; la comunicación por norma X-25, conocida como packet radio; o la captación de satélites meteorológicos como el meteosat, de posicionamiento (GPS Global Positioning System), proceso e información, como el INMARSAT; o en otro terreno la IBM lanzando satélites o la ITT vendiendo computadoras o sistemas móviles de comunicación, como los de mensajería, correo electrónico con estándares direccionales como el X-400, y otras tecnologías de la información, como las técnicas de compresión que envían más en menos tiempo, el EDI, la radio celular, incluso digital como la versión GSM, o las antenas parabólicas, que con terminales de pequeña amplitud (VSAT) nos permiten desde nuestra casa, vehículo, oficina o portátiles, interactivar con los satélites, y tantas cosas más extraordinariamente difíciles de observar.

Como consecuencia de una nueva y mejor lógica, que hace posible convertir en realidades operativas cosas que hace años ni siquiera Julio Veme fue capaz de imaginar, que revalorizan nuestro papel como seres "creadores*, capaces mediante nuestra imaginación de perfeccionar y ampliar nuestro «medio social» en uso de nuestra libertad, peculiaridad y creatividad, con la ayuda de proyectos inventados por personas.

¿Quién podía prever que una firma del prestigio de Kodak podría llegar a ver su negocio alterado y afectado en no poca medida por culpa de las industrias de la electrónica, y que lo mismo puede llegar a pasar con parte de las compañías discográficas?

La competencia hoy no siempre nos viene desde los campos más próximos a nuestro propio sector, porque la integración está dando lugar a procesos de interrelación e invasión de disciplinas que ofrecen funciones hasta hoy perfectamente diferentes, creando insospechadas alianzas y situaciones competitivas entre sectores, empresas y países que hasta hace poco nada tenían que ver entre sí.

Naturalmente, la reacción del mercado y de las firmas con prestigio no se ha hecho esperar, y miren por dónde a partir de a Kodak va a vender, con su marca, unas cámaras de video fabricadas, precisamente, por una empresa japonesa que hasta ahora ni era su competidor ni mucho menos su socio, la casa Matsushita, para competir con otras máquinas fotográficas digitales, por ejemplo de Canon o Logitec, que no necesitan el revelado para visualizar en pantallas o papel, instantáneamente, las imágenes obtenidas; las máquinas Polaroid que hacen lo propio; los libros electrónicos soportados por discos ópticos; máquinas portátiles visualizadoras y localizadoras de la información que precisamente nos interesa, y tantas cosas más. 


\section{Ridberth Ramírez Miranda}

Este hecho, impensable hace pocos años, de que los norteamericanos vendieran productos japoneses con su marca y a la inversa, en realidad es otra consecuencia natural del mismo proceso que comentamos, en el cual el acceso a un diverso sistema universal y la necesaria cooperación entre firmas que se complementan en algún nuevo aspecto, así como la universalización de la economía y hasta de la producción y competencia, son el resultado de las coincidencias de intereses derivadas de la internacionalización, y de unas tecnologías que generan insospechadas relaciones de cooperación o competencia, para mantener los respectivos prestigios en las correspondientes primicias y novedades, comprometiendo o repartiéndose responsabilidades y compartiendo su fama, beneficios y riesgos.

A poco que meditemos sobre el tema, y haciéndolo desde una nueva óptica, veremos cómo en este momento lo importante es, sobre todo, el hecho de disponer de una marca de prestigio, buena imagen, propaganda, mucho software -probablemente norteamericano-, y de estar respaldados por una buena organización, que también es inmaterial, así como una ágil personalización de lo que desea cada consumidor, usuario o comprador, confirma que la importancia de lo material disminuye y resulta relativamente menor a la hora de competir, en beneficio de la singularidad, funcionalidad, calidad, diseño, precio, garantía y servicios postventa.

Así, puesto que también en estos campos, como vender, opera de forma determinante el proceso de complejidad, espiritualización, comunicación, imaginación, motivación, integración, solidaridad e inmaterialización a que está sometido el mundo; esto resulta ser la clave de esta profunda transición que a tantos desconcierta.

\section{La urgencia de un nuevo proceso de ampliación}

Si la competencia es universal, a nadie puede sorprender que también 10 sean los mercados o el idioma, puesto que sólo con la presencia del producto o servicio, se establece en definitiva el verdadero reto de la competitividad de la comunicación, y el nuevo motor que exige superarnos, como manera de salir victoriosos en el seno de la superior complejidad que entre todos estamos alcanzando, lo que nos obliga a considerar los problemas de los demás también como nuestros.

Así las cosas, cada día constatamos la presencia de tu a tu, cuando no con ventaja para ellos en la escena internacional, de países y modos de producir y actuar con los que antes ni siquiera contábamos.

No hablemos sólo de Japón, que está en todas partes, actuando como verdadera punta de lanza en la apertura de mercados y como potente motor impulsor del cambio en tantos aspectos, con su fenomenal y admirable constancia, responsabilidad, agresividad, creatividad, seriedad, organización aplicada y tecnología, sino de otros países como Hong-Kong, Taiwan, 


\section{Evidencias para el cambio en un mundo globalizado, a partir de la realidad objetiva}

Corea del Sur, Filipinas, Malasia o Singapur, y otras economías principalmente capitalistas, cuyos espectaculares avances son reconocidos hasta por sus enemigos ideológicos.

Al haberse convertido, de hecho y de pronto, en emergentes competidores y naciones con las que ya hay que contar como tales, a la hora de lograr que lo que hacemos y pretendemos vender u ofrecer, sea mejor o por lo menos igual que lo suyo, estamos constatando que el proceso de universalización cada día avanza más.

Su principal denominador común radica en el hecho de que siendo casi todos pobres en recursos materiales, han sabido verlo hace tiempo v se han concentrado en la progresiva superior importancia de los bienes inmateriales (la información, la rapidez, la comunicación, la organización o formalización del conocimiento), lo que les ha permitido conceder absoluta prioridad al trabajo -sin tanta política-, a la organización y, sobre todo, en disponer de preparados recursos humanos e infraestructuras, porque al final un país es tan rico como las facilidades, la rapidez y formación de su gente.

Pues bien, la civilización sigue estando caracterizada prioritariamente por la producción de bienes e intercambio de servicios organizados, que enriquecen a las personas, ya que la agricultura necesita mucha menos gente porque se ha tecnificado, y a la industria le pasa lo mismo, al mecanizarse, automatizarse, robotizarse y organizarse en definitiva todo de otra manera, para abandonar así la producción estandarizada, orientándola en su lugar hacia los productos y servicios personalizados.

Lo que está ocurriendo es que asistimos a un claro proceso de ampliación que, de alguna forma, debemos considerar como algo nuevo, más interrelacionado, universal, vertiginoso $e$ integrador, puesto que las circunstancias que lo imponen hasta ahora no se habían dado, que podemos simbolizar en la importancia que cada día más representan las personas formadas, cuando además disponen de medios y los emplean automáticamente con rapidez.

Se trata de la ampliación cuantitativa y cualitativa del conocimiento $y$, consecuentemente, del número de ocupaciones posibles, hechas efectivas además en sitios y condiciones en las que antes no existían; fundamentalmente relacionadas con las propias actividades o sus servicios complementarios, pero en las que también la creatividad, ingenio, imagen, interdependencia y hasta el arte, acaparan el protagonismo, referido a un conocimiento y una técnica dominada y aplicada con la mentalidad y estrategia que se deriva de las visiones globales u holísticas que no analizan hechos aislados, sino absolutamente toda la realidad como un único todo.

Es, en definitiva, una ampliación de la cantidad, la intensidad y de la clase de las relaciones que se van estableciendo entre toda muerte de personas, países, disciplinas, actividades, o especialidades (antes independientes y que con sus nuevos «medios», conocimientos, técnicas, instrumentos, máquinas, infraestructuras e instituciones, forman ya verdaderos sistemas integrados que de hecho rápidamente constituyen y se mantienen en 


\section{Ridberth Ramírez Miranda}

constante contacto, al haberse organizado redes de comunicación que son las que hacen posible una nueva realidad dominada por la conectividad, gracias en no pequeña medida a la digitalización, como «Esperanto» o idioma entendido y compartido por la mayoría de quienes intervienen.

Es, por fin, una mejora y ampliación de los conocimientos acumulados por la humanidad a lo largo y ancho de un proceso de evolución, que cada vez nos ofrece más y mayores posibilidades de actuar más deprisa y mejor, principalmente como consecuencia de la interdependencia que resulta de la inducción, o integración de saberes o de cosas que antes fueron diferentes y distintas, y que ahora forman parte de un mismo sistema al compartir la misma unidad de sentido.

Todo en el seno de una red que une las partes en un solo todo, el que paradójicamente nos impone o reclama otra formación más completa, renovada, dinámica, genérica, actualizada, y constante información al día de muchos más campos, materias, países, cosas, mercados, situaciones y personas; todo esto nos permite alcanzar la visión holística que domine todo el conjunto para poder así actuar realmente con coherencia real en nuestro «medio», compartiendo siempre la indispensable unidad de sentido, que preside el que está presente en el nivel de conciencia que corresponde en cada momento a su nivel o sintonía.

Podríamos añadir muchos otros procesos aún pendientes de inducción o integración aunque algunos ya se intuyan- que participan de los aspectos comentados, y que añaden conocimientos hace poco desconocidos, como los saberes aplicables a unos océanos casi inexplorados, el mundo de la piscicultura, o el importante grupo al que conocemos como «tecnologías punta», de las que son una buena representación la adelantada microelectrónica, las operaciones con láser en medicina, la fibra óptica cableando océanos y continentes, el papel de los satélites en la paz y en la guerra, la robótica -que a su vez incluso fabrica robots-, las fundamentales tecnologías de la información y la comunicación, la ingeniería genética -por ejemplo, confirmando o rechazando la paternidad ante los tribunales-, la optoelectrónica aplicada en informática (cada vez en menor superficie por unidad, por ejemplo 1, (Gbyte en 5,25 pulgadas), las biotecnologías produciendo masivamente alimentos muy variados, los trasplantes en cirugía, los nuevos materiales más resistentes y ligeros, la medicina a distancia y tantísimas novedades e innovaciones hace poco hasta impensables están cambiando todo.

Pero dentro del proceso de ampliación, también merece un comentario especial la aludida transformación de actividades tradicionalmente industriales, cuyos resultados positivos principalmente provenían de las economías de escala derivadas de la fabricación en cadena de manera repetitiva, con resultados estandarizados, superada hoy por los productos personalizados, procesos o relaciones, cuyo principal componente no es ya la parte material, sino la coordinación de la información protagonizada por los múltiples conocimientos que cada vez, en mayor intensidad, velocidad y calidad, intervienen en esta mutación, que por su propia naturaleza es tan difícil de observar por ser la mayor parte de las veces inmaterial. por lo que ha 


\section{Evidencias para el cambio en un mundo globalizado, a partir de la realidad objetiva}

venido pasando inadvertida incluso a los analistas más sagaces, dando lugar a que aumentara aún más la propia confusión al no haber captado el cambio de sentido o dirección.

El proceso productor-comprador se ha invertido, convirtiendo al consumidor en el protagonista de lo que hay que hacer, puesto que es él quien define lo que quiere, en definitiva, y por tanto, lo que hay que producir, así como sus características y peculiaridades.

Hoy hay que hacer hincapié fundamentalmente en la ampliación que se está ofreciendo en aspectos tan inmateriales como la posibilidad de comunicar e informamos, la localización y utilización de conocimientos o la incorporación a las máquinas de facultades intelectuales como son la memoria, la capacidad de proceso, de seleccionar la alternativa mis probable, los lenguajes de nuevas generaciones con los que interactuamos con ellas o entre ellas, y sus sistemas lógicos al servicio del conocimiento, la formación, educación, puesta al día, la salud o la creatividad y comunicación entre personas que, a la postre, son quienes definen el sentido de sus actos, deseos, necesidades o acciones, prolongando su corporeidad física con técnicas que hacen el papel de ampliar nuestro «cuerpo actuante» $\mathrm{y}$, consecuentemente, la potencia de nuestras facultades.

En realidad, y una vez más, todo forma parte del superior proceso de inducción o integración, que se deriva de la mayor complejidad, puesto que poco a poco todo se relaciona con todo, conforme aumenta la comunicabilidad común a la cosificación, universalización, descentralización o la desprofesionalización, que acaban con la incomunicación, la centralización, la estandarización o con el propio especialismo aislado.

Así, poco a poco, se consolida un salto de nivel que dará origen a nuevas deducciones de superior categoría, que convierten la evolución en un proceso de continuo avance, creación, aumento de complejidad, velocidad, universalización, perfección y desarrollo, que nos implica a todos sin excepción, cada vez más deprisa en una u otra medida, y del que en cualquier caso formamos todos parte.

Al relacionar, ampliamos; al descentralizar diversificamos y distribuimos la responsabilidad, al desestandarizar y personalizar los productos y servicios lo mismo, y ante la intervención de la múltiple superespecialización también surge algo nuevo que incluye otra visión holística de la realidad o mentalidad apropiada, que reclama otra estrategia, con mayor grado de conectividad y comunicación, con eficaces nuevos «medios» y su correspondiente organización.

Todos estos planteamientos, lógicamente no dejan de dar lugar a nuevos problemas empleos y soluciones, en una realidad que cada vez se ve más claramente cómo está establecida en niveles de distinto sentido, que a su vez representan ámbitos coherentes de relación entre los que el ente de que se trate, cuya función queda definida siempre por el sentido superior que le corresponde, y su armonía con el "medio" o campo de relaciones, en el cual se lleva a cabo la misma cambiante acción propiamente dicha de la realidad, que materializa en definitiva el 


\section{Ridberth Ramírez Miranda}

superior y dinámico desenvolvimiento de nuestro proceso de evolución, da lugar a que continuamente surja algo nuevo.

En este momento la principal riqueza de la humanidad probablemente sea su diversidad de civilizaciones y culturas, y dentro de cada grupo de individuos aparentemente homogéneo, la acentuada singularidad de cada persona dentro del conjunto. Pero hay que afirmar que sólo la libertad puede permitir el desarrollo de seres que, compartiendo unos principios generales, pueden de verdad potenciar al máximo su peculiaridad.

Así como afortunadamente la evolución también es un proceso de ampliación de libertades, en el cual la diversidad personal experimenta un incremento o diversidad cada vez más notable, acentuado e irrepetible, sobre todo en función de nuestra mayor originalidad, creatividad o capacidad de ampliar nuestro «medio» e iniciativa, a partir de supuestos distintos, porque «crear» siempre implica diferenciarse de quien al permanecer estático o inmóvil no actuó en el mismo sentido, y esto solamente se consigue y se propicia con más libertad y con un mayor grado de diversidad, lo que incidentalmente fomenta la creatividad con el roce de diferentes visiones, relaciones e intercambio de puntos de vista peculiares de cada persona, con más situaciones, formaciones, especialidades, razas, culturas, mentalidades y estilos de vida, son los que contrastan nuestra singular originalidad, y nuestro grado superior de libertad, formación, ética, madurez y personalidad.

Por eso, aunque hubo un tiempo en que se temió que las conciencias pudieran llegar a unificarse al ser moldeadas por un mismo lenguaje, o por influjo de la propaganda y de los mismos medios de comunicación (TV, cine o enseñanza), a los que no discuto su enorme importancia e influencia, la verdad es que en el mundo libre en particular, la universalización asegura cada vez más el desarrollo y la existencia de individuos diferentes y diferenciados, que «crean» por tanto con mayor facilidad, cada uno a su manera, su «medio» propio contribuyen con su visión al avance del «medio social» que también evoluciona en beneficio de todos como algo inherente al propio proceso de creación, que mantiene consistentemente la evolución en su desenvolvimiento.

\section{Naturaleza del cambio}

Así resulta que en esta nueva época, por ejemplo, la automatización es más una manera de pensar y de enfocar y ver las cosas con mayor eficacia, que de hacerlas mejor que antes pero con otros instrumentos.

En realidad, cuando nos libramos de la concepción secuencial o lineal de pensar y actuar, porque entra en juego la integración, la instantaneidad, el acceso directo, la velocidad, la sincronización o el trabajo abordado en paralelo -o sea, al mismo tiempo-, pero dividido en parciales aspectos que conforman y completan el todo, y entran en juego las características de los 


\section{Evidencias para el cambio en un mundo globalizado, a partir de la realidad objetiva}

fenómenos eléctricos que intervienen en el proceso, sin importar dónde estemos, que nos permite por ejemplo la informática después de formalizar las aplicaciones que sustituyen a la mecánica, y no digamos nada de la artesanía o forma manual de trabajar, nos ofrecen la información rápidamente en la forma deseada, y los procesos empiezan a adquirir unas estructuras tan complejas que ya recuerdan más al maravilloso funcionamiento sincronizado de los organismos biológicos, que a los planteamientos manuales o puramente materiales de las máquinas.

La electrónica o ciencia de los electrones; la informática o información automática; la telemática, combinación de telecomunicaciones e informática, y otras tecnologías que han venido a prolongar nuestro "cuerpo actuante», incluyendo en nuestra acción una mayor capacidad de lógica, previsión, simulación, diseño, coordinación, memoria, cálculo y rapidez en la recuperación de la información, nos han proporcionado una precisión, una velocidad y, en general, una potencia y ampliación de nuestros sentidos y facultades desconocidas hasta ahora.

Por eso afirmar que la denominación "cerebro electrónico" es una verdadera barbaridad para quien conozca mínimamente lo que es un cerebro y lo que es un computador, porque si hay algo que no se parece absolutamente nada a un cerebro, es un computador. Por la misma razón me parece desacertado hablar de "inteligencia artificial", cuando «inteligire» es una voz latina que significa "penetrar", cosa que nunca hace ni hará un ordenador por sí mismo, por iniciativa propia, si antes no fue programado para repetir algo concebido previamente por un ser humano.

También es verdad que hoy son ya una realidad los "sistemas expertos" que, de alguna manera, cada día más, nos resolverán situaciones conocidas, pero no por eso tampoco llegarán a ser más "inteligentes" que un buen diccionario, ni por supuesto que sus autores, por mucho que estos hayan sido capaces de concretar con habilidad las explicaciones que luego nos proporcionará el instrumento; porque uno de los factores que está frenando el avance y la aplicación práctica de estos «medios» es, precisamente, el tiempo que perdemos en pugnas y comparaciones estúpidas que acaban generando rechazos viscerales, precisamente en un momento en el que no nos podemos permitir más-dilaciones ni la confusión de ideas que nos impide ponemos al día perdiendo nuestro tiempo en valorar si el hombre es más importante que la máquina, o la aportación de ésta es la que resuelve más cosas.

Sin embargo, debemos apresurarnos a admitir que el trabajo de las máquinas, cada vez con más frecuencia, resulta ser ventajoso, en el sentido de que puede combinar en un menor tiempo algo ya existente de forma más compleja, con mayor precisión y, en múltiples ocasiones, con más velocidad o seguridad que como lo hacemos corporal o manualmente los humanos, sin olvidar que prolonga y potencia nuestro "cuerpo actuante" cuando se presentan las ocasiones, si poseemos el instrumento y el correspondiente conocimiento y práctica de uso.

También debemos reconocerles su superioridad cuando se trata de labores reiterativas 


\section{Ridberth Ramírez Miranda}

o rutinarias en las que, a la larga, aparece en nosotros el cansancio intelectual o físico que hace que acabemos distrayéndonos y que, en definitiva, rindamos menos que las máquinas, nos pongamos en huelga o terminemos por equivocamos; algo parecido ocurre con el hecho de que, si han sido bien programadas, las máquinas sean más rápidas que nosotros haciendo cálculos, corrigiendo equivocaciones e incluso introduciendo, manipulando, reteniendo, recuperando o almacenando datos.

Con ser todo mucho, nunca el más perfecto robot será capaz de emular totalmente a un simple niño, ni llegará a alcanzar su impresionante grado de complejidad, entre otras cosas porque entes «creadores» capaces de ampliar sus funciones, solamente pueden llegar a lograrlo las personas, y a años luz de éstas, algunos seres vivos muy evolucionados, como podría ser -repito, de forma muy limitada- algún listísimo perro o delfín, al que tampoco se aproximará una máquina si hablamos de tomar iniciativas por su voluntad.

A poco que lo pensemos, deberíamos maravillamos, al analizar los distintos movimientos que es capaz de efectuar simplemente el brazo de una persona o los miembros de otros animales. Sin embargo, creo que ni siquiera estamos bien preparados para hacerlo artificialmente, porque se trata de un fenómeno intuitivo, en el que la complejidad se multiplica de forma exponencial, cada vez que se aumenta o añade otra nueva alternativa.

Es más la cantidad de movimientos que puede efectuar un brazo, probablemente, y a primera vista, nos puede parecer, si no ridículamente pequeña, por lo menos de las que no llaman la atención. y, sin embargo, bien mirado, el aumento de complejidad es un dato impresionante si lo comparamos con las limitaciones de un robot, por muy avanzado y perfecto que este sea.

Sólo multiplicando su complejidad y precio enormemente, lograríamos a adir un movimiento más a este proceso exponencial, en el que prácticamente ya hemos llegado a lo que hoy resulta ser el actual techo o límite de nuestro conocimiento aplicable en la práctica.

A pesar de todo esto, debemos irnos acostumbrando a la idea de que, a partir de 1975, el robot comercial ha empezado a ofrecemos cada vez más ventajas relativas en relación al trabajo del hombre, y, por lo tanto, la situación se ha vuelto irreversible y ya no hay quien la pare.

La multiplicación de estos ingenios pronto también será exponencial, puesto que ya se han resuelto -fábrica Fanuk, en Japón-, planteamientos operativos que permiten que un robot, programado para esto, haga otros robots, con lo cual nos hemos metido en un círculo infernal, hasta el extremo de que eso sí que va a representar una verdadera explosión demográfica. 
Evidencias para el cambio en un mundo globalizado, a partir de la realidad objetiva

Condenados a reproducirse por voluntad del hombre y a hacer lo que se les diga, por su incapacidad para ser inteligentes -repito, otra cosa es que hagan cosas inteligentes-, la fórmula de reduplicación resulta impresionantemente eficaz, tanto o más que la reproducción biológica, como también la ayuda que nos pueden aportar a las personas o empresas que simplemente los posean y sepan cómo se utilizan organizadamente.

\section{La urgencia del cambio en la sociedad}

A pesar de que todas estas evidencias se vienen gestando desde hace tiempo, debemos reconocer que, en alguna manera, el paso de una sociedad tradicional a la nueva creativa de relaciones de la comunicación, información, integración, universalización y el conocimiento, nos ha sorprendido a todos.

La prueba está en el mal uso y el lujo que supone ignorar el papel que debería estar jugando la televisión como formidable instrumento de divulgación, formación y actualización de las funciones de los nuevos «medios» disponibles, capaces de perfeccionar nuestro «cuerpo actuante» para facilitar la solución a problemas de la mejor manera.

No olvidemos que la mejor formación es la que integra a la mujer o el hombre en su «medio», y esto ya es posible si empezamos por saber lo que nuestro «medio» representa, lo que nos permitiría otra preparación que nos haría más completas y, por lo tanto, verdaderas personas.

A pesar de que desde siempre los propios recursos materiales han dependido de nuestro grado de comunicación, información y conocimientos, en un proceso histórico de ampliación de los propios seres humanos que continúa y continuará, con ejemplos tan recientes, como el de las mejoras que podemos esperar de la incorporación a nuestro ámbito de influencia del espacio exterior, o el descubrimiento de las energías limpias alternativas: solar, eólica o atómica, hoy ya fundamentalmente aplicable con fines pacíficos, cada vez contribuyen en mayor medida al éxito de nuestro reto de aproximarnos más a nuestro potencial techo de hominización.

También los satélites nos ofrecen a escala planetaria desde previsiones meteorológicas, inventarios de recursos naturales o la localización del plancton en el mar -porque allí es donde está la pesca-, o de nuestra posición geográfica en un momento dado, hasta fabulosas posibilidades de comunicación, no solamente de la voz sino de las imágenes -fijas o móviles-, datos, música, textos y memorias del mundo como los bancos de datos, incluso en ocasiones en movimiento como las películas, por poner sólo unos ejemplos.

Sin embargo, aún nos queda muchísimo camino por recorrer antes de llegar a 


\section{Ridberth Ramírez Miranda}

reconocer el derecho de toda persona a la información y la comunicación, por el mero hecho de existir, y hacerlo en un entorno que ofrezca a todos las mismas oportunidades para liberamos de la impresionante ignorancia con que nacemos, para que todos podamos aproximarnos a nuestra plenitud como seres humanos de acuerdo con nuestra singularidad, «medios», talentos y esfuerzos.

Por lo tanto, el verdadero reparto de riquezas no es ya el del dinero o el de las cosas de valor, sino el de la oportunidad de ampliar nuestro "cuerpo actuante» y en definitiva, progresivamente alcanzar cada vez un superior grado como persona con la contribución de la información-comunicación, las técnicas o los instrumentos y los conocimientos que, aplicados con la apropiada estrategia, nos permitan obtener ambas cosas y aprovechar las facilidades que, a lo mejor, tenemos delante de nosotros sin saberlo, como tan a menudo ocurre con algunos «medios» pendientes de ser formalizados por los hombres, por los que aún no saben que realmente podrían ser ya la solución a gran parte de nuestros problemas.

En síntesis, estamos implicados en un formidable proceso de formalización de conocimientos que, puestos a nuestro servicio por múltiples y sucesivas tomas de conciencia, coordinadas con la práctica, no solamente nos ofrecerán una vida espiritual, intelectual y material mejor y más fácil, sino que nos permitirán nada menos que llegar a ser más plenamente personas.

Para que llegue esto, hace falta ir ampliando nuestro "cuerpo actuante» y proporcionándonos actualizadas visiones de la realidad que corresponden con el nivel de conciencia o coherencia real que nos ha tocado vivir, dejando de ser en alguna medida como mancos, cojos, miopes, sordos, paralíticos o impedidos, si comparamos lo que es capaz nuestra mente y miembros con lo que la misma y los mismos llegarían a poder realizar en un mundo en el que de verdad todo se orientara a que cada ser humano llegará a ser tan completo como pudiera y quisiera, alcanzando así su propio techo de hominización en función de su esfuerzo, limitaciones, peculiaridades y talentos.

He aquí una parte importante del papel de la esperanza si somos capaces de comprenderla. Todos somos personas y vivimos en un único mundo. Apostemos por él y por nosotros, sin olvidar que sin coherencia la realidad es imperfecta o ni siquiera puede realmente existir. 
Evidencias para el cambio en un mundo globalizado, a partir de la realidad objetiva

\section{Referencias Bibliográficas}

TOFFLER, ALVIN.- "El Shock del Futuro", - Plaza y Janes Editores S.A. 1970.- "La Tercera Ola". - Plaza y Janes Editores S.A. 19 0.- "El Cambio del Poder". - Plaza y Janes Editores S.A. 1990.

PORTER, MICHAEL E.- "Estrategia Competitiva" Edit. CECSA 19 2.- "Ventaja Competitiva" Edit.

CECSA 1987.- "Ventaja Competitiva de las Naciones" Edit. CECSA 199.

HUNTINGTON, Samuel P.- "EL Choque de Civilizaciones", Edit. PAIDOS, 1992.-

"El Orden Político en las Sociedades en Cambio", Edit. PAIDOS, 1997.-

"La democratización a Finales del siglo XX", Edit. PAIDOS, 2000.

GADNER HOWAR (19 ) La nueva ciencia de la mente, Historia de la Revolución Cognitiva. Barcelona. Des. Paidos.

TAYLOR, F. (1990) Principios de la Administración Científica.

FAYOL, H. (1990) Administración General e industrial.

KLISBERG, BERNANDO (1999) Gerencia Social (como proyectos en contextos turbulentos.

KUHN, TOHOMAS (1996) La estructura de las revoluciones Científicas. México. Fondo de cultura Económico.

BARKER, (19 5) "Paradigmas" (El negocio de descubrir el futuro). Mc. Graw kill. Bogotá.

FUKUYAMA, FRANCIS, La gran ruptura: La naturaleza humana y la reconstrucción del orden social. Madrid, Atlántida, 1999. parte I ("La Gran Ruptura"). 